\title{
Evaluation of a Modified Habitat Suitability Index Model for Eastern Brook Trout: Implications for Efficient Habitat Assessment
}

\author{
Carl A. Favata ${ }^{\mathrm{a}}$, David R. Christensen ${ }^{\mathrm{a}}$, Robert Thompson ${ }^{\mathrm{a}}$, Kelly Anne McKeown ${ }^{\mathrm{a}}$, and \\ Jennifer A. Hanselman ${ }^{\mathrm{a}}$
}

\begin{abstract}
Species-specific habitat suitability models have potential for use in restoration efforts, but their efficiency still remains in question. As eastern brook trout, Salvelinus fontinalis, populations in New England have declined over the last few decades as a result of anthropogenic and natural impacts on critical habitat, habitat suitability models have become a common tool for conservation efforts. These models, however, have inherent flaws that prevent widespread and uniform use. To better adapt these models, the flaws must be properly addressed. Using a modified habitat suitability index (HSI) model developed for eastern brook trout, we explained the correlation between catch per unit effort (CPUE) of brook trout with designated HSI variables such as temperature, dominant substrate type, and percent riffle fines for nineteen reaches within the Westfield River watershed. CPUE was not significantly correlated with HSI outputs. A principal components analysis (PCA) was employed and revealed driving factors within the system. Four variables were shown to yield the highest explained variance over the first two axes: velocity, instream cover, percent pools, and thalweg depth. Evidence suggests that habitat assessment based around these core variables may lead to a more efficient and accurate assessment. Recommendations for improved methodologies include revised tolerance curves, a reworked index rating system, and revised model variables based on current field research. Alterations to existing models provide hope for more accurate assessment, and increased efficiency in conservation efforts.
\end{abstract}

Keywords: brook trout; restoration; HSI model; habitat suitability; habitat assessment

\section{Introduction}

Species driven ecological management and restoration has become an important focus in recent years in the eastern United States (Whiteley et al., 2012). States such as Massachusetts suffer from both anthropogenic and natural disturbances that affect local fisheries. There are approximately 3,000 dams throughout Massachusetts, approximately 250 of which still serve a functional purpose (Dam removal in Massachusetts, 2007). These structures impact ecosystems in many ways; effects may include altered temperatures, stream and river restructuring, altered turbidity and dissolved oxygen levels, build-up of organic wastes above the dam, and habitat fragmentation due to connectivity issues (Letcher et al., 2007; Niles et al., 2013). When conditions are altered, tolerance thresholds of key aquatic species are often exceeded. Streams and rivers also face natural disturbances such as hurricanes, floods, and tornadoes that may drastically alter habitat in a much shorter time. Habitat restoration is often necessary to ensure that a system is suitable for the survival of particular species of interest. A key example of such a species is the eastern brook trout (EBT), Salvelinus fontinalis.

In Massachusetts, native EBT populations have been greatly impacted over the last 100 years by a number of disturbances (Petty and Merriam, 2012). EBT are highly susceptible to habitat alterations such as increased temperatures, stream restructuring, low connectivity (Niles et al., 2013), and decreased flow rates (Hakala and Hartman, 2004). Throughout much of the Northeast, EBT habitat and population integrity have seen drastic declines (Conservation success index, 2012). Since EBT have narrow tolerance levels for a variety of environmental variables, they may often be considered an indicator species for cold, clean water that is suitable for a variety of important aquatic organisms (Lund et al., 2003; Waco and Taylor, 2010). To combat the decline in EBT populations, a variety of research has focused on assessment and rehabilitation of habitat (Petty and Merriam, 2012). Habitat assessment models are commonly used to accomplish this, but there currently exists no widespread uniform model (Petty and Merriam, 2012). One popular species-specific model was developed over two decades ago and is still widely used today, albeit in a variety of applications (e.g. wildlife management, habitat surveys, and wide scale land assessments).

Habitat Suitability Index (HSI) models (each speciesspecific) were developed in the early 1980's to better characterize habitat suitability based on target species (Habitat suitability index models, 2014). HSI models employ a set of environmental parameters related to critical and limiting biological tolerances of an organism, and provide a single index (HSI) based on a set of mathematical formulas. This index, ranging from zero to one, is directly related to a habitat's capacity to support a given species; the closer to one the output, the larger the theoretical population that the habitat could support. HSI models are readily available for many different species of animals and plants, giving them great versatility. They also are easily adaptable to meet the unique traits of any environment, factor in many different variables, and report a single index which allows for ease of longitudinal comparisons. These traits make the HSI model an optimal candidate to meet current assessment and restoration goals for native EBT populations. 
The decline of EBT over the last few decades has incited a demand for efficient methods to address this problem. In order to maximize efficiency there must be a model in which time, effort, required training, and monetary expense are minimized all while still providing quality, useful data. Previous studies have attempted to examine the usefulness and capability of various HSI models, garnering mixed results (Wesche et al., 1987; Hubert and Rahel, 1989; Roloff and Kernohan, 1999). Some studies examined HSI models using simple correlations and multiple-regressions of environmental variables to standing stock (Wesche and Goertler, 1987; Hubert and Rahel, 1989), while others have implemented systems of rating HSI models based on a set of custom scaled parameters (Roloff and Kernohan, 1999). Each study differed in the amount of HSI models being examined and by the type of species being utilized in each model, but may have lacked critical analysis of the variables being used within each model.

The intentions of this study were to examine the correlations of a single HSI model to the estimated population densities of EBT within the Westfield River watershed in western Massachusetts. Environmental variables were isolated and analyzed using a non-dimensional multivariate analysis to examine the effect of each variable on the variance within the dataset, as well as to study the intimate relationships between EBT and their habitat. Our goals were to 1) determine if a modified HSI model could accurately predict EBT densities, 2) determine the driving factors within the system, 3) address any flaws found within the model, and 4) propose adaptations that could help to increase efficiency of the model.

\section{Results}

There was no association between CPUE and HSI outputs $(r(19)=0.177$, d.f. $=17, \mathrm{p}>0.05)$; $($ Table 3$)$. A scatterplot of the data showed no apparent associations or developing trends (Figure 2). A statistically significant association between CPUE data and the all stage SI was found $(r \quad 19)=0.746$, d.f. $=17, \mathrm{p}<0.0001) ;($ Table 3). PCA performed on square root transformed data of four isolated variables accounted for $83.9 \%$ cumulative variance over the first two axes. Variable (Figure 3) and site data (Figure 4) were plotted to define axes gradients and examine driving factors within the system.

Table 3: Results of Spearman's rho rank correlation. CPUE was found to be significantly correlated with SI outputs for variables affecting all life stages $(\mathrm{p}<0.001)$ and Adult SI outputs $(\mathrm{p}=0.05)$. No other SI or HSI outputs were significantly correlated with CPUE data.

\begin{tabular}{|c|c|c|c|c|c|c|c|c|}
\hline & & & $\begin{array}{c}\text { Adult } \\
\text { SI }\end{array}$ & $\begin{array}{c}\text { Juvenile } \\
\text { SI }\end{array}$ & $\begin{array}{c}\text { Fry } \\
\text { SI }\end{array}$ & $\begin{array}{c}\text { Embryo } \\
\text { SI }\end{array}$ & $\begin{array}{c}\text { All stage } \\
\text { SI }\end{array}$ & HSI \\
\hline \multirow[t]{2}{*}{$\begin{array}{c}\text { Spearman's } \\
\text { rho }\end{array}$} & CPUE & $\begin{array}{l}\text { Correlation } \\
\text { Coefficient }\end{array}$ & 0.455 & 0.395 & 0.175 & -0.243 & 0.746 & 0.177 \\
\hline & & $\mathrm{p}$ (2-tailed) & 0.050 & 0.095 & 0.474 & 0.315 & $<0.0001$ & 0.468 \\
\hline
\end{tabular}

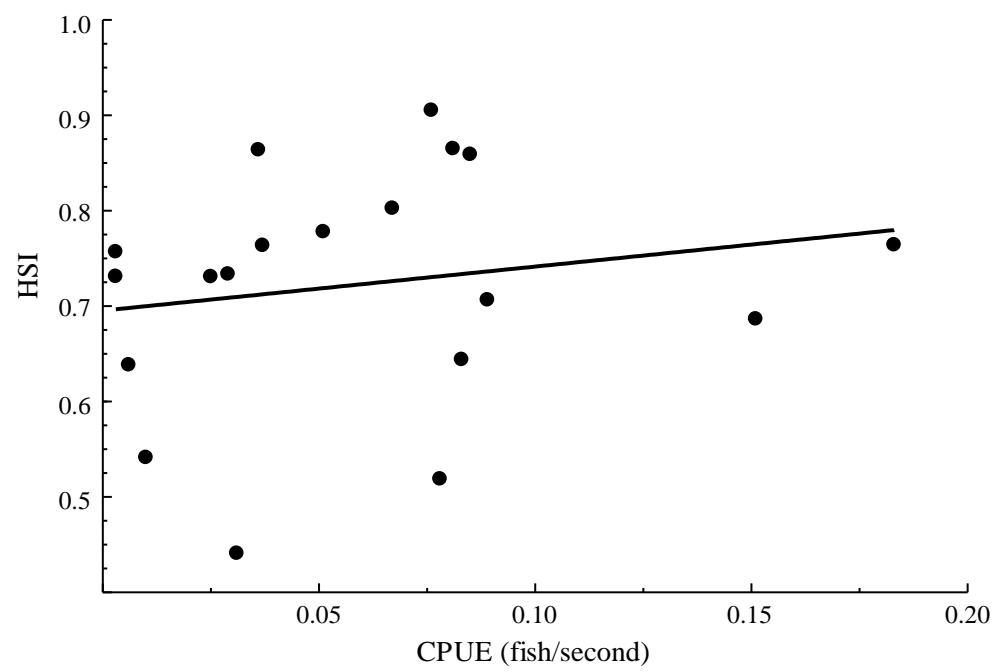

Figure 2: Plot of HSI and CPUE data. There was no clear association between HSI outputs and CPUE data. Data were clustered between 0 and 0.10 fish per second, and no HSI values fell below 0.4 . 


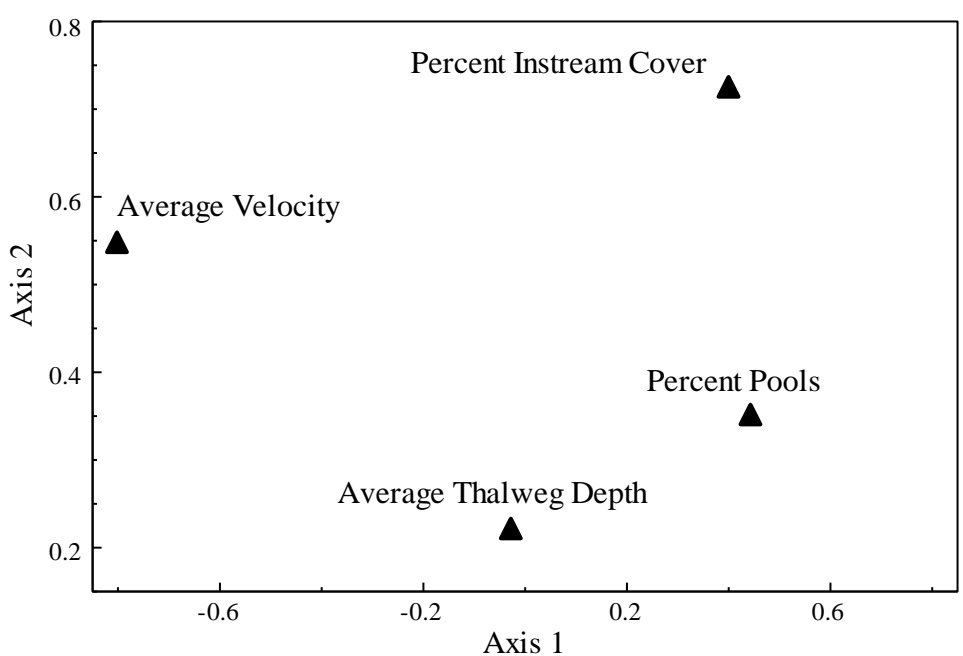

Figure 3: Results from a PCA of square root transformed environmental data showing relative positions of 4 variables which accounted for $83.9 \%$ of the cumulative variance. These data were used to help define axes gradients along with site data. Driving factors along Axis 1 included average velocity (-0.80201) and percent pools (0.44286). Driving factors along Axis 2 included percent instream cover (0.72556) and average thalweg depth (0.22180).

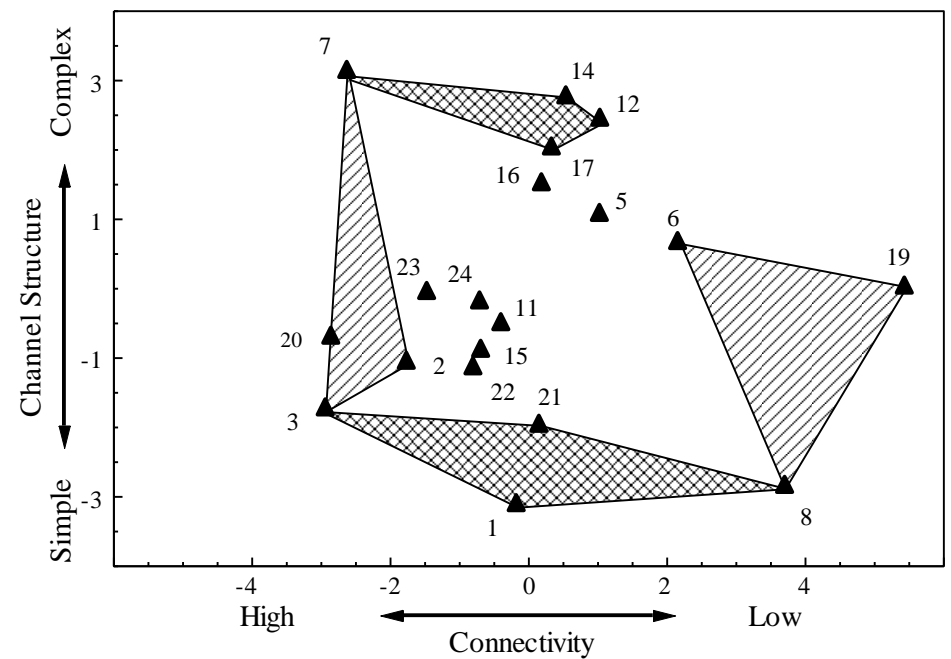

Figure 4: Site data and axes gradients resulting from a PCA of square root transformed environmental data. Sites grouped across Axis 1 represented a gradient of stream connectivity; velocity, percent pools, and instream cover were all found to influence data along this axis. Sites were separated along Axis 2 based on a gradient based on channel structure; instream cover and thalweg depth both influenced data across this axis.

\section{Discussion}

\section{Model accuracy and feasibility}

No clear associations were seen between CPUE data and HSI outputs. The limited accuracy of this model has supported further modification and improvements. Previous studies have demonstrated a similar lack of relationship between HSI model outputs and salmonid population data (Wesche et. al., 1987; Hubert and Rahel, 1989; Roloff and Kernohan, 1999). Although some statistical associations exist between model variables and CPUE data, it is advised that this model be used with restraint in regards to assessment and restoration work. These associations suggest that each system may be highly dynamic, and are driven by different variables. Application of this model to watershed analysis and description based upon target species may prove useful.
Multivariate analysis was crucial in determining the driving factors in this study.

\section{PCA interpretation}

PCA yielded axes gradients which were defined by the physical characteristics of each reach. Data were grouped along Axis 1 based on levels of connectivity relating to average velocity, instream cover, and percent pools (Figure 4). Sites with low connectivity were characterized by limited velocity, high percentages of pools, and higher rates of instream cover due to detritus build-up, inappropriate culverts, or human-made dams. Sites with high connectivity exhibited sufficient velocity, a near fifty percent pool ratio, and reaches consisted of zero to 25 percent instream cover. Data were grouped along Axis 2 based on a gradient of channel structure complexity in relation to average thalweg 
depth, percent instream cover, and average velocity (Figure 4). Sites with high thalweg depth, high instream cover, and high velocity were shown to have a complex channel structure while those experiencing low rates of each variable exhibited a simple structure. Results suggested that EBT critical habitat variables were defined as those relating to connectivity and channel structure, with an emphasis on suitability for migration of juvenile and adult EBT. These critical variables accounted for the highest explained variance within the model, and also contributed to the SI which showed the strongest association to CPUE data.

\section{Driving factors}

Multiple PCAs alluded to environmental data which were heavily influenced by four variables directly relating to connectivity and channel structure; there was a distinct uniformity seen in the rest of the data set. Water quality variables which fell within the optimum range of tolerance curves in each site included dissolved oxygen, temperature, and $\mathrm{pH}$. Variables relating to average size of spawning substrates were also similar between sites, indicating that at least five percent of the reach met optimal substrate size standards for spawning. These data were supported by the presence of naturally reproducing EBT in each reach as indicated by fish survey data. The lack of variation between these data most likely occurred due to similarity between reaches; each reach sampled was of comparable size and substrate composition, and had sufficient flow and canopy coverage to support adequate water temperatures and dissolved oxygen levels during low water periods. Water quality and substrate variables thus were not useful in this system, and would be best utilized when examining populations of EBT in areas that suffer from lack of sufficient forest canopy, border urban environments, or may be affected by acid rain or pollution. Although recent research has shown that water quality variables can serve as limiting factors in EBT fitness in certain systems (Lund et al., 2003; Baldigo et al., 2005), the Westfield River watershed hosts an assemblage of mountain-fed headwater and low order streams that meet minimum water quality tolerances for EBT. The limiting variables in this system were thus related to the unique physical properties of each reach.

Variables distinctive to each reach included percent instream cover $\left(V_{6}\right)$, average velocity $\left(V_{10}\right)$, percent pools $\left(V_{5}\right)$, and thalweg depth $\left(V_{4}\right)$. These variables accounted for the majority of variance across Axis 1 and 2 , and were determined to be the most limiting variables within nineteen sites in the watershed. Recent research has supported these findings, and has concluded that variables relating to connectivity (Hartman and Logan, 2010) and channel structure (Johnson, 2008; Ecret and Mihuc, 2013) affected brook trout habitat use and dispersal patterns in low order streams. Instream cover was highly variable between sites, perhaps as a consequence of environmental disturbance (periods of extreme flow rates), dominant substrate type, and excess allochthonous input into the system. Velocity also fluctuated between sites and was dependent on gradient, instream structure, and flow source among other variables. Percent pools, or the pool-riffle ratio also varied considerably due in part to flow rates and instream structure. Thalweg depth differed between sites and was dependent on a variety of variables including instream cover, stream gradient, and environmental disturbance. Research has supported that these four variables can have a profound impacts on EBT migration and status in a system. Niles et al. (2013) recently demonstrated how spontaneous alterations in channel structure and connectivity, such as the removal of a dam or impoundment, can have dramatic effects on the dispersal patterns of brook trout in Appalachian low order streams. Ecret and Mihuc (2013) explored the biological aspect and importance of similar variables to multiple developmental stages of EBT in Adirondack streams, while also demonstrating a temporal effect on dispersal behavior as well. Salmonids may often be highly mobile, and evidence in recent literature suggests negative relationships between low connectivity and instream structure (Ecret and Mihuc, 2013; Niles et al., 2013). It was clear that developing connectivity and structure-based models with a focus on continuity within this system might optimize the quality of assessment.

\section{Model flaws and proposed alterations}

Results were not founded without defect, however. Through implementation, several flaws which posed a threat to the accuracy of the correlation were identified and examined. These inaccuracies pertain to methodological shortcomings of the HSI model used, and were overlooked during sampling in order to accurately test the model as it was designed. We wished to address these flaws later, and to offer alterations for future model modification and development.

One downfall of the HSI model for EBT was that it was based on a set of assumptions (Raleigh et al., 1982), which were in turn developed using research published during the early to mid- $20^{\text {th }}$ century. Nearly a century later, some of this research could certainly be outdated, resulting in a model operating under false assumptions. It has only been within the last century that drastic declines in EBT populations have been recognized (Hudy et al., 2005; Petty and Merriam, 2012). Since HSI model accuracy hinges on precise tolerance curves, it is necessary to base these models on current data that best represents the actual tolerances of EBT. These data should be collected using surveys as well as in situ and laboratory experiments. It is recommended that further research explore updated tolerance curves for EBT.

Indices may often group distinctly different data points into the same index rating, rendering it impossible to discern slight differences and trends within a data set. For example, water temperatures in this study ranged from 10 to $15{ }^{\circ} \mathrm{C}$, yet none of the nineteen sites sampled recorded the exact same temperature. When combined with tolerance curves and assigned an index, each site yielded an index rating of 1 for water temperature, clearly showing a lack of variation. This flaw could partially account for the lack of correlation between data. While indices can be helpful by characterizing an entire system into an easily understandable and comparable index, they also severely limited the accuracy of this model. In order to increase definition, future research should focus on utilizing more raw data, and reworking the index scaling system to include a wider range of values. A weighted model where emphasis is put on critical habitat variables specific to a system could prove to be more beneficial and result in a higher quality assessment.

Several sampling flaws were also acknowledged during this study. Performance of the model required the sampler to estimate several variables (e.g. percent shade, percent 
instream cover, percent streamside vegetation, etc.) through visual cues. Though these values were quantitative, they may have been inherently skewed by sampler bias (to control for this bias, the same sampler was used throughout the study). Longitudinal studies would also have to account for such bias, where it may not necessarily be feasible to have the same sampler for an extended period of time. The unmodified HSI model for EBT published by Raleigh et al. (1982) also required sampling at various times of the year (i.e. low water months and spawning times) and included variables which required continuous measurement (average temperatures, $\mathrm{pH}$, dissolved oxygen, base flow). These requirements make replicating the model a time-consuming task. Although the modified instantaneous model showed no significant relationship to CPUE, it is important to note that no longitudinal variables were found to account for any significant amount of variance; this provides support for continued development of an instantaneous assessment model. Further modifications to the model may greatly reduce sampler estimated variables through the use of directly quantifiable methods (e.g. a fish eye lens system to measure canopy cover, or random transect sampling for instream content). Ultimately, there will always be variables that require continued monitoring, but they should be kept to a minimum to control for time and cost; this may ensure successful longitudinal application of such a model, which has been a downfall of other assessment methods (Petty and Merriam, 2012).

Establishing accurate population data is crucial to understanding how populations are affected by acute and long-term habitat alteration. If models are left to operate solely on the assumptions set by research there will never be a direct way to monitor population fluctuations. Using current population data in conjunction with these modified assessment models would allow for simultaneous comparisons to be made. In this case, if populations shifted due to sources outside of the model's capability, the data would be able to immediately assess this change, and proper research could further measure such a trend. Ecosystems are very dynamic and may shift quickly and drastically when exposed to environmental stressors or disturbances. Proper research precautions must be met to combat these shifts.

\section{Conclusions}

As EBT populations continue to decrease it will become more vital to understand the underlying causes of these declines, assess the current habitat and population status, and to propose plans of action to lessen these effects. It is well known that environmental as well as anthropogenic stressors can negatively affect these fish. Habitat assessment models will continue to be a crucial part in helping to collect data and understand these effects. Current models use a variety of methods to assess habitat in relation to species tolerances and optimal habitat preference, but fail in providing a cost and time-effective strategy which may be universally applicable. This study has demonstrated the potential contained within a modified HSI model for EBT while also addressing several central flaws that may disrupt the accuracy and efficiency of the model. This HSI model has proven useful for improved decision making and hypothesis testing, but lacks the reliability and accuracy to be used as an effective management tool. Proposed adaptations could prove beneficial to improving one such model. This study has demonstrated and supported that each system may be highly variable, and models must be tailored to the specific characteristics of each system in order to produce an accurate assessment. Future research must continue to work with and modify habitat assessment models in order to overcome inaccuracies. Although specific to a single assessment model, these conclusions may be applicable to other similar models for various species, and may even highlight troubling trends consistent within various HSI models.

\section{Experimental Procedures}

\section{Data Collection}

Catch per unit effort (CPUE) fish survey data outsourced by the Massachusetts Division of Fisheries and Wildlife were used in conjunction with data collected at twenty-four reaches on twenty streams within the Westfield River watershed in western Massachusetts (Figure 1). Fish count surveys were completed via backpack electrofishing during limiting months (July to October) in 2001 (sites 20-22), 2006 (site 23), 2010 (sites 1-12), 2011 (sites 13-16, 24), and 2012 (sites 17-19). CPUE was derived from fish caught over total sampling time. Five reaches were identified as possible ephemeral streams or were associated with abnormal flow restrictions, and were excluded from this study (Table 1). Fourteen reaches were dominated by naturally reproducing EBT, while the remaining five reaches contained EBT along with a variety of predators and possible competitors (Table 1). Streams ranged from headwater to medium sized (first to fifth order).

Methodology for an EBT HSI model developed by Raleigh et al. (1982) was modified to include sixteen of the seventeen variables, excluding average annual base flow $\left(\mathrm{V}_{14}\right)$; (Table 2); since study protocol called for instantaneous measurements, average annual base flow was not feasible to include in the model, and its exclusion was not deemed detrimental to the study. Environmental data collection dates ranged from August to early October, coinciding with Massachusetts Division of Fisheries and Wildlife data collected in years prior.

\section{Statistical Analysis}

Due to abnormal distribution of data and unequal variances, nonparametric Spearman's rank correlations were performed to assess any possible relationship between CPUE, life stage suitability index (SI) and HSI outputs (PASW v.20.0). To further understand the driving factors within each system a principal components analysis (PCA) was employed (McCune and Mefford, 2011). The PCA allowed for an assessment of the variance within the data set while helping to isolate those variables that contributed most to the variance. PCA results were graphed and examined using eigenvalue outputs (PSI v.10.5). Multiple arch effects led to a reduction in environmental parameters which did not contribute to the explained variance, or were similar to other variables in the model. This process reduced redundancy within the model variables, which may have been adversely affecting the PCA. Square root transformed data for four environmental variables were analyzed using a PCA, yielding clearer results. 
Table 1: Site descriptions and locations of twenty-four reaches in the Westfield River watershed. Five sites* were not sampled due to the absence of sufficient flowing water, and highlight the high variability of available habitat over a short span of time. An additional five sites** were dominated by species other than EBT. Unnamed reaches were designated with UNT (unnamed tributary) along with the connecting body of water.

\begin{tabular}{|c|c|c|c|c|}
\hline Site ID & Site Name & Latitude & Longitude & Town \\
\hline 1 & UNT to Middle Branch & 42.37027 & -72.99124 & Middlefield \\
\hline 2 & UNT to Westfield River (1) & 42.23420 & -72.88173 & Huntington \\
\hline 3 & UNT to Westfield River (2) & 42.48291 & -72.92923 & Cummington \\
\hline $4^{*}$ & UNT to Westfield River (3) & 42.48500 & -72.94685 & Cummington \\
\hline 5 & Sykes Brook & 42.30017 & -72.87752 & Huntington \\
\hline 6 & Hollister Brook & 42.10277 & -72.85838 & Granville \\
\hline 7 & Whitmarsh Brook & 42.44232 & -72.95671 & Worthington \\
\hline $8^{*}$ & Hamilton Brook & 42.27454 & -73.06976 & Becket \\
\hline $9 *$ & Shop Brook & 42.34715 & -72.80827 & Westhampton \\
\hline 10 & Crow Brook & 42.23641 & -72.83936 & Montgomery \\
\hline 11 & Wigwam Brook & 42.18252 & -72.88087 & Russell \\
\hline 12 & Cold Brook & 42.23609 & -72.90777 & Huntington \\
\hline $13^{*}$ & UNT to Watts Stream & 42.37626 & -72.93918 & Worthington \\
\hline 14 & Pixley Brook & 42.20222 & -72.98164 & Blandford \\
\hline 15 & Mica Mill Brook & 42.25312 & -72.92170 & Chester \\
\hline 16 & Bartlett Brook & 42.49991 & -72.94585 & Plainfield \\
\hline 17 & UNT to Fuller Brook & 42.42673 & -72.82733 & Goshen \\
\hline $18^{*}$ & UNT to Sodum Brook & 42.14374 & -72.85909 & Russell \\
\hline 19 & Falls Brook & 42.16686 & -72.92267 & Blandford \\
\hline $20 * *$ & Pond Brook (2) & 42.16769 & -72.96786 & Blandford \\
\hline $21 * *$ & May Hollow Brook & 42.09781 & -72.68166 & Agawam \\
\hline $22 * *$ & Pond Brook (1) & 42.15657 & -72.70679 & Westfield \\
\hline $23 * *$ & Case Brook & 42.16722 & -72.97934 & Blandford \\
\hline $24 * *$ & Watson Brook & 42.17575 & -72.98622 & Blandford \\
\hline
\end{tabular}


Table 2: A concise description of the modified methodology derived from an HSI model for brook trout developed by the United States Fish and Wildlife Service (Raleigh et al., 1982).

\begin{tabular}{|c|c|c|}
\hline Variable & Model Variable & Revised Methodology \\
\hline Max. Water Temp. & $\mathrm{V}_{1} / \mathrm{V}_{2}$ & Measured water temperature below water surface in non-riffle area. \\
\hline Min. Dissolved Oxygen & $\mathrm{V}_{3}$ & Measured dissolved oxygen below water surface in non-riffle run area. \\
\hline Avg. Thalweg Depth & $\mathrm{V}_{4}$ & Sampled the entire length of the reach as stated in sampling \\
\hline Avg. Velocity & $\mathrm{V}_{5}$ & $\begin{array}{l}\text { Measured the top } 20 \% \text { and bottom } 80 \% \text { water column every } 15 \text { meters along } \\
\text { the reach, starting upstream and working downstream, and taking the average. }\end{array}$ \\
\hline$\%$ Instream Cover & $\mathrm{V}_{6}$ & $\begin{array}{l}\text { Measured visually by the sampler. "Cover" defined as underwater vegetation } \\
\text { and substrate large enough to create a break in flow, and shelter for a brook } \\
\text { trout, or at least } 0.093 \text { square meters. }\end{array}$ \\
\hline Avg. Substrate Size & $\mathrm{V}_{7}$ & $\begin{array}{l}\text { If a potential spawning area was available or present within the reach } \\
\text { (characterized by gravel and cobble substrate between } 0.3 \text { and } 8 \mathrm{~cm} \text { and } \\
\text { flowing), a total of } 5 \% \text { of the total reach area was analyzed, and substrate size } \\
\text { measured using a gravelometer. }\end{array}$ \\
\hline$\%$ Substrate Size & $\mathrm{V}_{8}$ & $\begin{array}{l}\text { Substrate in the } 10-40 \mathrm{~cm} \text { class was counted and a percentage of the total } \\
\text { reach assigned at the sampler's discretion. }\end{array}$ \\
\hline Dominant Substrate & $\mathrm{V}_{9}$ & $\begin{array}{l}\text { In riffle run areas, substrate type was considered dominant if greater than } \\
50 \% \text { total area. Options are: Rubble/small boulders/aquatic vegetation only, } \\
\text { Rubble/gravel/boulders/fines occur in equal amounts or gravel is dominant, } \\
\text { fines/bedrock/large boulders dominant where rubble and gravel are } \\
\text { insignificant. }\end{array}$ \\
\hline$\%$ Pools & $\mathrm{V}_{10}$ & $\begin{array}{l}\text { Number of pools compared to the total reach area, assigned at discretion of } \\
\text { sampler. }\end{array}$ \\
\hline Avg. \% Vegetation & $\mathrm{V}_{11}$ & $\begin{array}{l}\text { Percent of trees/shrubs/grasses/bareground along the stream bank were } \\
\text { estimated by the sampler. Estimates may exceed } 100 \% \text { in cases of overhang. }\end{array}$ \\
\hline$\%$ Streamside Veg. & $\mathrm{V}_{12}$ & $\begin{array}{l}\text { Bank erosion factors estimated by the sampler and assigned a percentage } \\
\text { value of the total bank composition. }\end{array}$ \\
\hline $\mathrm{pH}$ & $\mathrm{V}_{13}$ & Measured below water surface in non-riffle run area. \\
\hline Pool Class & $\mathrm{V}_{15}$ & $\begin{array}{l}\text { Assigned using a numerical system based on average pool characteristics: } \\
1=\text { large and deep pools where bottom is obscured } \\
2=\text { Moderate size and depth pools, bottom partially obscured } \\
3=\text { small or shallow pools, typically provide minimal shade and current }\end{array}$ \\
\hline$\%$ Riffle Fines & $\mathrm{V}_{16}$ & $\begin{array}{l}\text { Percent fines }(<3 \mathrm{~mm}) \text { in riffle run and spawning areas estimated by the } \\
\text { sampler. A percentage of the total area was assigned. }\end{array}$ \\
\hline$\%$ Midday Shade & $\mathrm{V}_{17}$ & $\begin{array}{l}\text { Estimated by sampler, between } 10 \mathrm{am} \text { and } 2 \mathrm{pm} \text {, the amount of shade } \\
\text { provided by the canopy within the reach (by percent of total area covered) }\end{array}$ \\
\hline
\end{tabular}




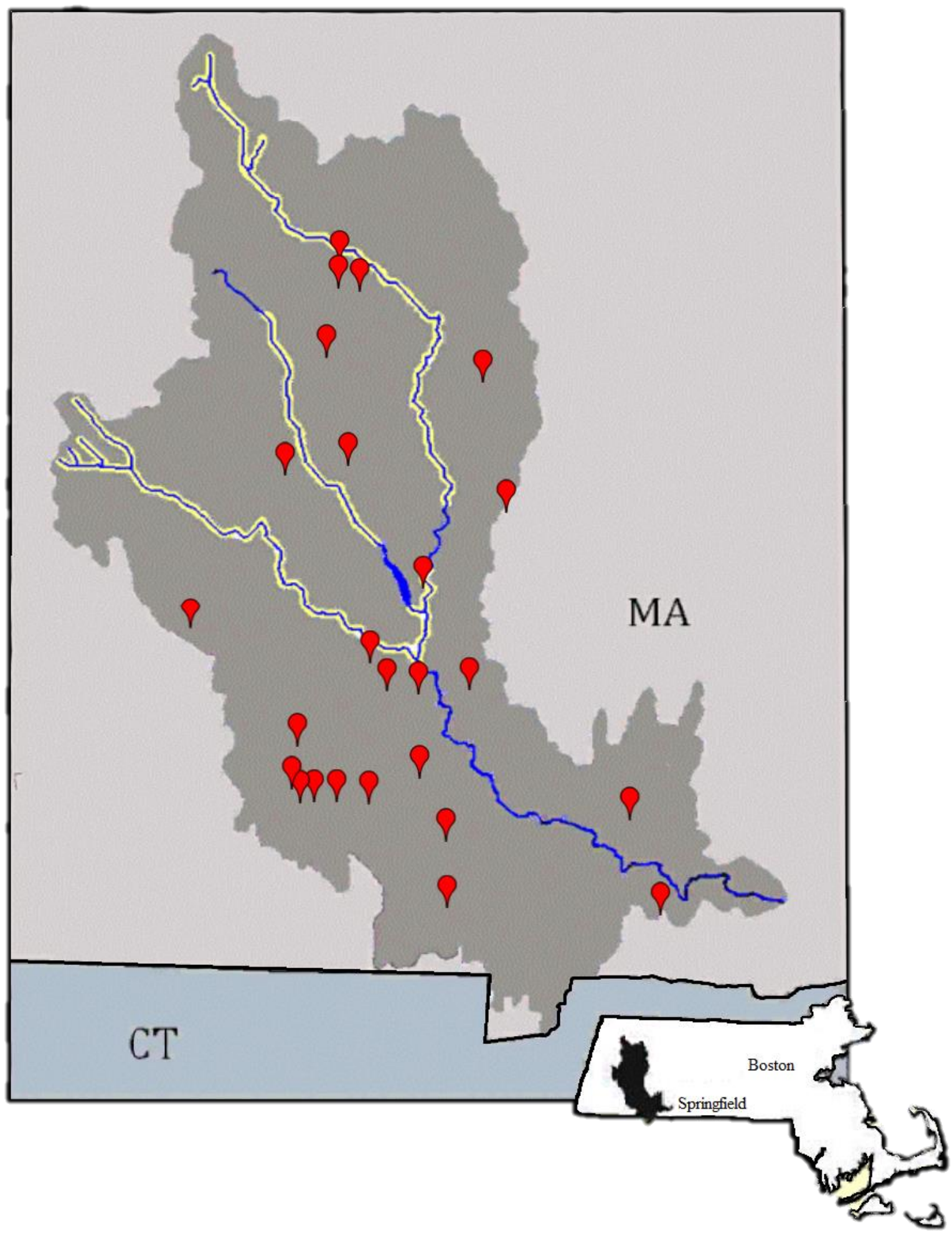

Figure 1: Relative locations of sites sampled throughout the Westfield River watershed in western Massachusetts (image extracted and edited from http://www.nps.gov/). 


\section{Acknowledgements}

We thank the Westfield State University Biology department for facilitating this project, and providing all necessary equipment and resources required for field sampling. We thank the Westfield State University Honors Program for their role in organizing and hosting this project under the commonwealth honors scholar program. We also thank L. Fontaine and the Massachusetts Division of Fish and Wildlife for their cooperation and support, and for providing necessary survey data needed to complete this study. We are indebted to D. Phelps and R. Bressette for their volunteer work in the field during data collection and to C. Muszynski for her GIS collaboration during data analysis.

\section{References}

Baldigo BP, Murdoch PS, Burns DA. 2005. Stream acidification and mortality of brook trout (Salvelinus fontinalis) in response to timber harvest in Catskill mountain watersheds, New York, USA. Can J Fish Aquat Sci, 62(5): 1168-1183.

Blanchfield PJ, Ridgway MS. 1997. Reproductive timing and use of red sites by lake-spawning brook trout (Salvelinus fontinalis). Can J Fish Aquat Sci, 54: 747-756.

Butryn RS, Parrish DL, Rizzo DM. 2013. Summer stream temperature metrics for predicting brook trout (Salvelinus fontinalis) distribution in streams. Hydrobiologia, 703(1): 47-57.

Conservation success index. 2012. Retrieved from http://www.tu.org/csi.

Dam removal in Massachusetts. 2007. Retrieved from http://www.mass.gov/eea/docs/eea/water/damremovalguidance.pdf

Ecret J, Mihuc TB. 2013. Brook trout (Salvelinus fontinalis) habitat use and dispersal patterns in New York Adirondack mountain headwater streams. Northeast Nat, 20(1): 19-36.

Habitat suitability index models. 2014. Retrieved from http://www.nwrc.usgs.gov/wdb/pub/hsi/hsiintro.htm.

Hakala JP, Hartman KJ. 2004. Drought effect on stream morphology and brook trout (Salvelinus fontinalis) populations in forested headwater streams. Hydrobiologia, 515(1-3): 203-213.

Hartman KJ, Logan MN. 2010. Movement and habitat use by transplanted adult brook trout in an Appalachian headwater stream. Northeast Nat, 17(3): 357-372.

Johnson JH. 2008. Seasonal habitat use of brook trout and juvenile Atlantic salmon in a tributary of Lake Ontario. Northeast Nat, 15(3): 363-374.
Stranko SA, Hilderbrand RH, Morgan II RP, Staley MW, Becker AJ, Roseberry-Lincoln A, Perry ES, Jacobson PT. 2008. Brook trout declines with land cover and temperature changes in Maryland. N Am J Fish Manage. 28: 12231232.

Hubert W, Rahel F. 1989. Relations of physical habitat to abundance of four nongame fishes in high-plains streams: a test of habitat suitability index models. N Am J Fish Manage. 9: 332-340.

Letcher BH, Nislow KH, Coombs JA, Dubreuil TL. 2007. Population response to habitat fragmentation in a streamdwelling brook trout population. Plos Biol, 2(11).

Lund SG, Lund MEA, Tufts BL. 2003. Red blood cell hsp 70 mRNA and protein as bioindicators of temperature stress in the brook trout (Salvelinus fontinalis). Can J Fish Aquat Sci, 60(4): 460-470.

McCune, B. and M. J. Mefford. 2011. PC-ORD. Multivariate Analysis of Ecological Data. Version 6. MjM Software, Gleneden Beach, Oregon, U.S.A.

Niles JM, Hartman KJ, Keyser P. 2013. Short-term effects of beaver dam removal on brook trout in an Appalachian headwater stream. Northeast Nat, 20(3): 540-551.

Nislow KH, Lowe WH. 2006. Influences of logging history and riparian forest characteristics on macroinvertebrates and brook trout (Salvelinus fontinalis) in headwater streams (New Hampshire, U.S.A.). Freshwater Biol. 51: 388-397.

Petty JT, Merriam EP. 2012. Brook Trout Restoration. Natur Educ Knowl. 3(7):17

Raleigh RF. 1982. Habitat suitability index models: Brook trout. U.S. Department Interior, Fish Wildlife Service FWS/OBS-82/10.24. 42 pp.

Roloff G, Kernohan B. 1999. Evaluating reliability of habitat suitability index models. Wildlife Soc B. 27: 973-985.

Waco KE, Taylor WW. 2010. The influence of groundwater withdrawal and land use changes on brook charr (Salvelinus fontinalis) thermal habitat in two coldwater tributaries in Michigan, U.S.A. Hydrobiologia, 650(1): 101-116.

Wesche T, Goertler C, Hubert W. 1987. Modified habitat suitability index model for brown trout in southeastern Wyoming. N Am J Fish Manage. 7: 232-237.

Whiteley AR, Coombs JA., Hudy M, Robinson Z, Nislow $\mathrm{KH}$, Letcher BH. 2012. Sampling strategies for estimating brook trout effective population size. Conserv Genet, 13(3): 625-637. 